\title{
Intrapulmonary drug administration in neonatal and paediatric critical care: a comprehensive review
}

\author{
D. De Luca*, P. Cogo\# ${ }^{\#}$ E. Zecca ${ }^{\top}$, M. Piastra ${ }^{+}$, D. Pietrini' ${ }^{+}$, A. Tridente ${ }^{\S}$, \\ G. Conti ${ }^{+}$and V.P. Carnielli*
}

ABSTRACT: Administration of drugs directly into the respiratory tree first was proposed a long time ago. Surfactant is the paradigmatic example of such therapies. Many other drugs have been used in the same way and further compounds are under investigation for this aim. In the last two decades, despite the wide number of drugs available for direct lung administration in critical care patients, few controlled data exist regarding their use in neonates and infants.

This review will focus on drugs clinically available in a critical care setting for neonates and infants, including bronchodilators, pulmonary vasodilators, anti-inflammatory agents, mucolytics, resuscitative anti-infective agents, surfactants and other drugs.

We provide an evidence-based comprehensive review of drugs available for intratracheal administration in paediatric and neonatal critical care and we examine possible advantages and risks for each proposed indication.

KEYWORDS: Critical care, infant, inhaled drug

$\mathbf{T}$ he administration of drugs directly into the respiratory tree has been used since early 1950s to reach the target organ or when other routes are unavailable [1]. Delivering drugs into the lung is generally useful in the intensive care setting, in which a prompt response is often needed. Ventilatory support is a cornerstone of treatment in paediatric, and especially neonatal, intensive care, due to the high prevalence of respiratory diseases in these settings [2]. This may explain the numerous data on existing drugs and the current development of new studies specifically targeted for direct lung administration in such populations by nebulisation, direct tracheal instillation or as a gas mixture via a ventilator.

This review will focus on drugs already available or in advanced clinical research for critically ill neonates and infants, while many drugs which are under development (i.e. phospholipase A2 inhibitors, phosphodiesterase inhibitors, endothelin-1 antagonists, carbon monoxide, new surfactants and xenon) will not be reviewed. We propose a classification of presently available drugs in eight classes, according to their main mechanism of action, as shown in table 1 .

\section{BRONCHODILATORS}

\section{$\beta_{2}$-agonists}

Historically, $\beta_{2}$-agonists were considered of little efficacy in children $<2$ yrs of age, because of the lack of $\beta_{2}$-receptors on the bronchial mucosa [3]. A Cochrane meta-analysis does not encourage further studies in this population [3]. However, no study included in the meta-analysis had been performed in intensive care units (ICUs). Prolonged oxygen therapy is often needed in ICU patients and may induce smooth muscle hypertrophy; thus, ventilated babies could be more responsive to $\beta 2$ agonists than less critical infants [4]. This is especially true for neonates with bronchopulmonary dysplasia (BPD) or for infants with oxygen dependentheart diseases. The response to $\beta_{2}$-agonists in children with severe asthma appears influenced by its receptor gene polymorphisms and is more evident in babies homozygous for Gly at amino acid position 16 [5]. Therefore, the potential benefits arising from their use should be weighted against the risks in each case [6].

$\beta_{2}$-agonists were studied in the early 1980s for the prevention or early treatment of BPD in pre-term infants $[7,8]$. However, a Cochrane review demonstrated no significant effect on any major outcomes

\section{AFFILIATIONS}

*Neonatal Intensive Care Unit, Women and Children's Hospital

"G.Salesi", Polytechnical University of Marche, Ancona,

\#Paediatric Intensive Care Unit, Dept of Paediatrics, University of Padova, Padua,

"Division of Neonatology, Dept of

Paediatrics, and

+Paediatric Intensive Care Unit, Dept of Anaesthesiology and Intensive Care, University Hospital "A.Gemelli", Catholic University of the Sacred Heart, Rome, Italy.

${ }^{\text {s }}$ Sheffield Teaching Hospitals NHS

Foundation Trust, Sheffield, UK.

CORRESPONDENCE

D. De Luca

Terapia Intensiva Neonatale

Ospedale Materno-Infantile "G.Salesi"

Università Politecnica delle Marche

v. F. Corridoni 11

60123 Ancona

Italy

E-mail: dm.deluca@fastwebnet.it

Received:

Feb 132010

Accepted after revision:

June 192010 
[9]. Despite these findings, several $\beta_{2}$-agonists are still widely used in neonatal ICUs with different administration schedules [10]. Aerosolisation of bronchodilators during mechanical ventilation transiently reduces airway resistance $(\sim 30 \%)$ and improves lung compliance and forced vital capacity [9]. The use of $\beta_{2}$-agonists should be restricted to certain ventilated neonates with signs of bronchial obstruction (BPD spells) or increased work of breathing [9]. Moreover, BPD infants may experience an increased airway instability after the $\beta_{2}$-agonists administration and this should be also taken into account [11]. No recommendations can be provided in support of specific molecules, because of the lack of specific comparative trials.

$\beta_{2}$-agonists have also been used for neonatal hyperkalaemia, since in vitro studies showed an increasing potassium flux after salbutamol activation of the sodium/potassium adenosine triphosphatase $\left(\mathrm{Na}^{+} / \mathrm{K}^{+}\right.$-ATPase) [12]. A randomised, controlled trial of nebulised albuterol versus saline in 19 preterm neonates showed a significant reduction in serum potassium at $4 \mathrm{~h}$ and $8 \mathrm{~h}$ in the treatment group [13]. Albuterol appears to be well tolerated by pre-term infants but side-effects include tachycardia, tremor and hyperglycaemia. A 2007 Cochrane meta-analysis of interventions for hyperkalaemia identified only three trials for inclusion in the review and did not provide definite recommendations. Specific trials comparing $\beta_{2}$-agonists against insulin/dextrose infusion are needed [14].

\section{Anticholinergics}

Ipratropium bromide is the most common anticholinergic drug. When added to $\beta_{2}$-agonists, it is effective in reducing hospital admission and improving lung mechanics in severe paediatric asthma exacerbation $[15,16]$. Nevertheless, no data are available in ICU patients and the drug had no effect for the treatment of children already admitted to the hospital [17]. Scanty data are available for babies $<2$ yrs old and a recent
Cochrane review showed no clear benefits in terms of duration of hospitalisation or oxygenation improvement [18]. Therefore, the use of anticholinergics in paediatric ICU does not appear to be justified over the standard therapies, on the basis of evidence available to date [19].

Ipratropium administered to neonates on mechanical ventilation beyond the acute phase of respiratory distress syndrome (iRDS) induced short term improvements of pulmonary mechanics [20], similar to $\beta_{2}$-agonists [8]. Recently, a crossover trial of ipratropium against $\beta_{2}$-agonists in neonates ventilated for $>5$ days showed a slightly greater reduction of airway resistance with ipratropium compared with terbutaline [21]. Targeted studies are needed to verify the effect of ipratropium on major neonatal outcomes.

\section{Adrenaline}

Adrenaline has been widely used and investigated for the treatment of bronchiolitis and croup in infancy. A metaanalysis of 14 trials demonstrated the superiority of adrenaline over $\beta_{2}$-agonists for acute bronchiolitis, in terms of oxygenation, clinical improvement and reduction of heart and respiratory rate [22]. Five randomised clinical trials published after this meta-analysis reported on the inferiority of adrenaline versus other bronchodilators: these findings include a lack of benefit for any outcome in acute bronchiolitis [23, 24], no difference in outcomes [25, 26] or slower recovery [27] compared to treatment with $\beta_{2}$-agonists.

Nonetheless, none of the previously mentioned studies included ICU patients. Theoretically, adrenaline could be useful for croup or bronchiolitis [28], since mucosal oedema is an important component of airway obstruction in these conditions, the combined $\alpha / \beta$ effect of adrenaline might cause bronchiolar vasoconstriction and reduce mucous production [29].

TABLE 1 Classification of drugs available for direct administration into the respiratory tree in paediatric and neonatal critical care and indications proposed in the literature

Available drugs

$\beta_{2}$-agonists, adrenaline, anticholinergics

iNO, prostacyclin and analogues, ENO

Pulmonary vasodilators

Anti-inflammatory drugs

Mucolytics

Hypertonic saline, acetylcysteine, dornase- $\alpha$

Resuscitative drugs

Anti-infective

Surfactant

Miscellaneous
Heliox, furosemide, superoxide dismutase
Proposed indications

Bronchiolitis, croup, asthma, TTN, bronchospam, post-extubation respiratory failure

PPHN, ARDS, bronchiolitis

Bronchiolitis, croup, BPD, PPHN, sepsis, NEC, meconium aspiration sydrome

Atelectasis, mucus plugging, cystic fibrosis, status asthmaticus, long-term mechanical ventilation, bronchiolitis, smoke inhalation acute lung injury, BPD

Cardiopulmonary resuscitation, refractory shock Bronchiolitis, bacterial and fungine respiratory infections, ventilator-associated pneumonia, influenza

iRDS, meconium aspiration syndrome, congenital diaphragmatic hernia, infection-related respiratory failure, aspiration syndrome, ARDS

Asthma, bronchiolitis, croup, post-extubation stridor, ARDS air leaks, upper airway obstruction, BPD 
LEVIN et al. [30] recently published the only trial in an ICU setting, comparing $\beta_{2}$-agonists and adrenaline in 22 bronchiolitis infants on mechanical ventilation. Both drugs significantly decreased respiratory system resistance and peak inspiratory pressure but their clinical relevance was questionable. ARGENT et al. [31] enrolled infants with severe croup, showing that adrenaline improved respiratory mechanics but the effect was small and transient, requiring repeated or continuous drug administrations.

In neonates, adrenaline has been used for several indications. Given its role in fetal lung fluid absorption, adrenaline was proposed for the treatment of transient tachypnoea of the neonate (TTN). However, neither side-effects nor clear benefits were demonstrated in 20 neonates with TTN [32]. Adrenaline has also been used for the prevention of post-extubation respiratory failure or stridor and, empirically, for BPD spells [33]. Only one trial studied adrenaline in this context: COURTNEY et al. [33] randomised 45 long-term ventilated neonates to postextubation racemic adrenaline or placebo and reported no effect on ventilatory function. A Cochrane meta-analysis recently concluded that there is no evidence to support or refute the use of nebulised adrenaline in neonates [34].

\section{PULMONARY VASODILATORS Inhaled nitric oxide}

Nitric oxide (NO) is synthesised in the vascular endothelium by NO synthase and causes smooth muscle relaxation by increasing the intracellular cyclic guanosine monophosphate (cGMP). Inhaled (i)NO is the first-choice drug for persistent pulmonary hypertension of the neonate (PPHN) [35]. Its overall response rate is $\sim 75 \%$, depending on the definition, the underlying disease, the type of ventilation and genetics [35]. A Cochrane meta-analysis [36] confirmed that iNO achieves oxygenation improvement and significant reduction in the combined outcome of extracorporeal membrane oxygenation (ECMO) or mortality (relative risk (RR) $0.63,95 \%$ CI 0.54-0.75; number needing treatment (NNT) 5.3). Based on these trials, iNO therapy was approved for the use in neonates $\geqslant 34$ weeks gestation with hypoxaemic respiratory failure [37] using a dose of $20 \mathrm{ppm}$, although lower doses may be successful in a significant number of patients and may facilitate the weaning [35]. The response can reach $50 \%$ and $65 \%$ in PPHN secondary to meconium aspiration and iRDS, respectively, but is quite poor in PPHN due to congenital diaphragmatic hernia [38]. Concomitant parenchymal diseases may worsen oxygenation, hiding the clinical response, and iNO seems more effective during high frequency oscillatory ventilation (HFOV) than in conventional modalities [39]. Decreasing pulmonary pressures with iNO administration may be detrimental in neonates with patent ductus arteriosus or heart defects with a right-to-left shunt and right ventricledependent systemic circulation [40]. Finally, pulmonary vascular abnormalities of the NO-cGMP pathway might lessen iNO efficacy or PPHN may be mainly due to other biochemical pathways [39].

Doses $>20 \mathrm{ppm}$ have no benefit in patients unresponsive to the standard dosage $[35,41]$. Based on initial trials, iNO is generally instituted when the oxygenation index (OI) is $>25$. Nevertheless, two trials indicate that earlier use of iNO in respiratory failure might be useful [42, 43]. GonZÁLES et al. [42] randomised 56 neonates to early (when OI $>10$ ) or standard iNO and found oxygenation improvement and reduction in oxygen therapy duration. KONDURI GANESH et al. [43], reported similar oxygenation improvement, but neither survival, nor need for ECMO or their combined outcome improved. Weaning from iNO may sometimes be problematic, especially in case of long-lasting administration, because iNO may suppress endogenous NO production with a negative feedback on NO synthase [44]: OI $<5$ predicted successful withdrawal (sensitivity $75 \%$ ) [45].

The use of iNO in pre-term neonates is still debated. It has been tested as early rescue for pulmonary hypertension and respiratory failure, and for treatment and prevention of BPD. A recent systematic review [46] of the 11 trials undertaken to date showed that routine iNO administration for BPD prevention led to slight but significant reduction in death or BPD (RR 0.9, 95\% CI 0.84-0.99) and brain injury (RR 0.70, 95\% CI 0.53-0.91). Rescue use did not result in the same advantages and was even associated with a trend towards increased incidence of severe brain injury. It is possible that babies sick enough to fulfill the criteria for a "rescue" administration may already have lung damage that is too severe to be improved with iNO. The European Nitric Oxide (EUNO) trial randomised 800 neonates to receive early (within the first $24 \mathrm{~h}$ ) $5 \mathrm{ppm}$ iNO or placebo, if they presented with mild-tomoderate respiratory failure. This is a more recent trial and was targeted also to deliver iNO after the extubation. iNO was administered through endotracheal tubes or continuous positive airway pressure (CPAP) for an average of 16 days. The results were recently presented at the European Academy of Paediatrics meeting and no improvement was found in survival, BPD rate or any other outcomes [47]. A 1-yr followup study of pre-term babies who received iNO gave an improved quality-adjusted survival, but the difference was marginal [48].

Experience with iNO in paediatric intensive care is more limited than in the neonatal critical care setting. Only one clinical trial tested iNO for adult and paediatric acute respiratory distress syndrome (ARDS), showing a transient improvement in oxygenation with no effect on mortality [49]. A larger paediatric experience with iNO comes from the perioperative care of congenital heart diseases, including numerous anecdotal reports [45]. The only randomised controlled trial [50] concluded that $10 \mathrm{ppm}$ iNO prophylactic administration reduced hypertensive events and ventilation time, without affecting mortality. iNO has been also studied as a bronchodilator in infants with severe respiratory syncytial virus (RSV) bronchiolitis without significant effect [51].

The European Society for Paediatric and Neonatal Intensive Care and the European Society for Paediatric Research [45] recommended iNO use for term and late pre-term neonates with respiratory failure and suggested a short iNO trial in congenital heart disease infants at risk of pulmonary hypertension. iNO should be continued only if there is documented evidence of haemodynamic improvement.

\section{Prostacycline and analogues}

Prostacycline (prostaglandin (PG) $\mathrm{I}_{2}$ ) is a natural pulmonary vasodilator synthesised in endothelial cells and it stimulates 
adenylate cyclase-mediated conversion of adenosine triphosphate to cyclic adenosine monophosphate, which relaxes the vascular smooth muscle [52]. Since $\mathrm{PGI}_{2}$ and iNO pursue the same goal through two different messengers, a synergistic effect has been observed in preclinical studies and in some uncontrolled clinical observations [53, 54]. Epoprostenol (the clinically available synthetic $\mathrm{PGI}_{2}$ ) has been given intratracheally as a bolus or continuous infusion for PPHN in five pre-term infants with iRDS or sepsis-related respiratory failure [54,55] and in four term infants affected by intractable PPHN [56]. All babies survived except for one with alveolar capillary dysplasia. Epoprostenol is provided in an alkaline buffer that could theoretically harm the lung epithelium [57]. A synthetic $\mathrm{PGE}_{1}$ has also been used in 20 neonates with promising results [58]. Iloprost is a synthetic carbacyclin analogue which has a longer half-life than epoprostenol with fewer rebounds after the administration and is available in a neutral solution [59]. Iloprost has been used in six term and pre-term babies, alone or together with iNO, and significantly improved oxygenation $[57,60]$.

Few data are available on the use of prostacyclines in paediatric critical care. In children with congenital heart diseases, both epoprostenol and iloprost are powerful vasodilators $[61,62]$. In particular, iloprost was as efficacious as iNO for infants with pulmonary hypertension and congenital heart defects but was not synergistic with iNO [61]. 14 infants and children with acute lung injury received nebulised epoprostenol and oxygenation improved with NNT $=1.8$ [63]. Since all these molecules are liquid, nebulisation is needed. The effectiveness of nebulisation during HFOV is unknown and, hence, some prefer to use the direct instillation or continuous tracheal infusion $[55,56]$.

\section{Inhaled O-nitrosoethanol gas}

Endogenous NO concentrations are low and most NO present in airways is bound in complexes called S-nitrosothiols (SNOs), which are the natural mediators of the matching between ventilation and perfusion [64]. Airway SNOs are resistant to toxic reactions with oxygen and their concentrations cannot adequately be restored with iNO [65]. The use of such molecules should therefore provide potent pulmonary vasodilation without the possible side-effects of iNO because they cannot react with oxygen. In a pilot study, O-nitrosoethanol (ENO) was used to restore SNOs and efficaciously improved both oxygenation and haemodynamics in PPHN neonates. ENO produced no side-effects and its sudden discontinuation did not impair oxygenation, as it usually happens with iNO [64].

\section{ANTI-INFLAMMATORY DRUGS}

\section{Pentoxifylline}

Nebulised pentoxifylline was used initially by LAUTERBACH and LAUTERBACH [66], for the prevention of BPD. Pentoxifylline may have diuretic, bronchodilator, fibrin reduction and antiinflammatory effects $[67,68]$. Pentoxifylline, administered to 150 very low birth-weight infants during mechanical ventilation or CPAP, reduced BPD (-27\%; OR 0.32, 95\% CI 0.11-0.94; $\mathrm{p}=0.039)$ with no apparent side-effects [69]. Intravenously administered pentoxifylline may reduce mortality in neonatal sepsis [70] and has been proposed for PPHN and necrotising enterocolitis [67, 71], but no data are available about its intratracheal use in such conditions.

\section{Steroids}

Inhaled steroids have been extensively studied in neonatal critical care for prevention or treatment of BPD. In the last decade, $>10$ studies have been published with wide differences regarding populations, dosages, preparations and way of delivering. Two recent Cochrane reviews found no significant effects on mortality or BPD, either at 28 days or 36 weeks postmenstrual age $[72,73]$. Moreover, no differences in effectiveness between inhaled and systemic steroids were found and concerns have been raised about the amount that actually reaches the lung during nebulisation [73]. A newly EU-funded clinical trial, NEUROSIS (Neonatal European Study of Inhaled Steroids) [74], should clarify the effect of inhaled budesonide against placebo in babies between 23 and 27 weeks' gestation, the population at highest risk for developing BPD. Recently, YEH et al. [75] studied the administration of budesonide, vehicled by exogenous surfactant to 116 neonates with severe iRDS [75]. In this randomised pilot trial they found a significant reduction in death or BPD $(-29 \% ; p=0.003)$ and fewer days on oxygen $(-7.1 \% ; p=0.047)$. No systemic effects were found, with only $4 \%$ of the instilled dose being found in the blood. Further studies are needed on this interesting approach, which is likely to effectively deliver steroids into the peripheral lung.

Inhaled steroids have also been studied in term neonates for meconium aspiration syndrome. They suppressed tumour necrosis factor $\alpha$ in tracheal aspirates and treated neonates showed earlier radiological improvement and earlier full enteral feeding, shorter hospital stay and oxygen dependence $[76,77]$. These results were confirmed in another randomised trial of 99 neonates, in which drug efficacy was similar for both intratracheal and intravenous steroids [78].

\section{Cromolyn}

Cromolyn is a well known anti-inflammatory agent inhibiting neutrophil migration and superoxide radical release [79]. During the 1990s, two randomised trials $[80,81]$ gave conflicting results regarding inhaled cromolyn efficacy to reduce mortality and BPD rate in pre-term neonates. A Cochrane meta-analysis of the pooled data showed no beneficial effect for cromolyn treatment. Current evidence does not support the use cromolyn in pre-term neonates for BPD prevention [82].

\section{Clara cell secretory protein}

Clara cell secretory protein (CC10) is the natural inhibitor of phospholipase A2, the enzyme responsible for surfactant catabolism [83] and has various anti-inflammatory properties [79]. Several basic studies suggested a role for CC10 in the pathophysiology of lung diseases such as BPD [84], bronchiolitis [85], asthma [86], and ARDS [87]. A randomised phase I/II trial in 22 pre-term neonates showed recombinant human (r-hu-)CC10 to be safe and able to decrease lung inflammatory markers [88]. No other data are available and r-hu-CC10 remains to be tested in a specifically designed trial.

\section{RESUSCITATIVE DRUGS}

This category includes lipid-soluble drugs comprised under the LEAN acronym (lidocaine, adrenaline, atropine and naloxone), 
which can be used during advanced resuscitation when venous or intraosseous lines are unavailable [89]. Following installation, these drugs should be followed by a flush of isotonic saline and a minimum of five ventilations. Chest compressions should be temporarily held during the administration, to prevent expelling the drugs in a simulated cough.

These drugs are recommended by resuscitation guidelines issued by scientific societies, but few controlled data have been published $[89,90]$. Vasopressin may also be given intratracheally; however, its clinical utility has been questioned, even if administered intravenously [89,91]. Administration of resuscitative drugs into the trachea may result in lower systemic concentrations, as compared to the intravascular routes [89, 92]. Neonatal Resuscitation Program guidelines recommend endotracheal adrenaline at doses (up to 10 times) higher than the intravenous ones [90].

\section{MUCOLYTICS}

\section{Hypertonic saline}

Inhaled hypertonic saline, because of its high osmolarity, which attracts submucosal water, may reduce the airway oedema and decrease the mucous thickness [93]. Hypertonic saline improves clinical score and shortens hospital stay (-0.94 days, 95\% CI -1.48-0.40 days; $\mathrm{p}=0.0006)$ in bronchiolitis [94], while it improves respiratory mechanics and reduces pulmonary exacerbations in cystic fibrosis children [95]. Hypertonic saline could theoretically be useful during neonatal respiratory diseases characterised by high mucous production and inflammation, but no data are available.

\section{Dornase- $\alpha$}

Dornase- $\alpha$ is a recombinant enzyme well known for the treatment of cystic fibrosis: it reduces viscosity of airway secretions, breaking bonds between extracellular DNA molecules derived from leukocytes and infectious agents [79]. In the ICU setting, dornase- $\alpha$ was efficacious for resolving atelectasis in children without cystic fibrosis ventilated long-term [96]. Dornase- $\alpha$ also reduced ventilation days, while there was a trend towards shorter ICU stay and less atelectasis in congenital heart disease children [97]. Treatment seems as more efficacious, as more bacteria or neutrophil are present in tracheal aspirate fluid [98]. In four children, dornase- $\alpha$ [99-102] also allowed a quick resolution of refractory status asthmaticus, in which other conventional therapies or bronchoscopic lavage failed to resolve airway obstruction.

Finally, nebulised or instilled dornase- $\alpha$ has a dramatic effect in resolving atelectasis and tracheal tube plugging in term and pre-term neonates [103, 104].

\section{Acetylcysteine}

Acetylcysteine is a well known sulfhydryl mucolytic agent [79]. In a paediatric ICU, a retrospective cohort study investigated the joint nebulisation of heparin and acetylcysteine in 90 children affected by burns and smoke inhalation lung injury. Treatment reduced extubation failure, atelectasis and mortality [105].

Only one randomised crossover trial studied intratracheal acetylcysteine in pre-term neonates to treat BPD. Acetylcysteine failed to cause any benefit and even increases airway resistances and bradycardia episodes [106].

\section{ANTI-INFECTIVE AGENTS Ribavirin}

Nebulised ribavirin has been used in severe RSV bronchiolitis because of its antiproliferative effect. Its use has decreased overtime and it appears to have limited clinical usefulness [107]. Meta-analyses of three ribavirin studies in paediatric critical care settings showed a significant decrease in ventilator days and length of hospital stay [108, 109]. A recent retrospective cohort study examined the effect of ribavirine combined with intramuscular anti-RSV monoclonal antibodies (palivizumab) and found a decreased mortality compared to historical data [110]. No data are available regarding the use of ribavirin in neonates.

\section{Antibiotics}

Inhaled antibiotics have been frequently used during infectious episodes in cystic fibrosis patients or for gram-negative and $P$. carinii infections in immunocompromised patients [111]. As for other drugs, the majority of data are coming from nonICU patients and, since the early 1970s, several small studies have been published on the use of nebulised antibiotics, such as gentamycin, ceftazidim and colistin, or other anti-infective agents, such as pentamidine [112].

In the last 2 yrs, inhaled tobramycin has been investigated in paediatric populations. The first trial randomised 247 cystic fibrosis children to receive tobramycin or placebo for 20 weeks and improvement in lung mechanics, microbiological status and lost school days was demonstrated [113]. RATJEN et al. [114] randomised 88 cystic fibrosis children to receive either 28 or 56 days of inhaled tobramycin demonstrating the usefulness of this therapy, but no differences due to its duration. Very recently, inhaled aztreonam has been also investigated and gained approval for its use in cystic fibrosis [115]. In randomised clinical trials, aztreonam demonstrated significant improvement in lung mechanics, and microbiological and clinical status [116].

Despite these intriguing results, inhaled antibiotics clear bacteria but do not seem to reduce inflammation in cystic fibrosis [117]. In fact, another recent trial comparing systemic versus inhaled therapy showed less cellular infiltrate in patients treated systemically [118]. Mucus obstruction has been indicated as a possible cause, and the joint administration of antibiotics and dornase- $\alpha$ has been recently proposed to address this issue [119]. Given these lines of evidence, a 2004 European consensus was reached that the optimal form of therapy is still not established [120] and a Cochrane review found insufficient evidence to recommend specific treatment strategies [121]. Notably, none of the previously mentioned data came from an ICU setting.

Very recently, intrapulmonary antibiotic administration has also been proposed for the treatment of tuberculosis in order to reduce the exposure of Mycobacteria to subtherapeutic levels [122]. Specific trials are needed for the inhaled treatment of tuberculosis in paediatric and neonatal critical care.

With similar aims, in the ICU setting, inhaled antibiotics have been proposed for the management of ventilator-associated 
pneumonia (VAP). No data are available in paediatric and neonatal critical care settings, but a meta-analysis of available trials in adults demonstrated a reduced incidence of VAP for patients receiving inhaled prophylaxis [123], while less evidence is available for the VAP treatment [124]. However, there is growing evidence in favour of inhaled antibiotics for multidrug-resistant respiratory infections in adults admitted to ICU [125]. Specific trials are needed to verify possible benefits in paediatric and neonatal critical care.

\section{Amphotericin B}

Inhaled amphotericin B has been proposed for both treatment and prophylaxis of fungal infections since 1959 [126]. It is available in pure, lipidic or liposomal preparations and might have a role in transplant recipient and immunocompromised patients [127]. In some of these cases, amphotericin B has also been directly instilled under fibre-optic bronchoscopy [128]. Nevertheless, no data are available either in paediatric or in neonatal critical care.

\section{Zanamivir}

Zanamivir is a micronised, dry-powder inhaled antiviral agent that inhibits the neuraminidase active site on the surface of influenza viruses A and B. Zanamivir has been approved for treatment and prophylaxis of influenza in children $>5$ yrs of age [129]. At present, no study has been published regarding its use in the ICU and doubts have been raised about effective powder delivery during ventilation and in smaller children, although in this case, the help of parents should ensure correct administration [130]. Specific studies about the ICU use of zanamivir on infants and neonates are needed.

\section{SURFACTANT}

Surfactant is a cornerstone of neonatal intensive care. Recently, both the American Academy of Paediatrics and a European consensus conference issued specific guidelines for the management of iRDS [131, 132]. Surfactant should be given as prophylaxis or treatment, as early as possible, to all pre-term infants with worsening respiratory distress. Natural surfactants should be preferred, as they reduce pulmonary air leaks and mortality. In particular, porcine surfactant (poractant- $\alpha$ ) leads to improved survival compared to the others [131, 132]. Multiple doses, rather than a single one, in babies with ongoing respiratory failure further improved clinical outcomes in terms of survival, air leaks, mechanical ventilation requirements and necrotising enterocolitis incidence [133].

A Cochrane meta-analysis of four trials of surfactant therapy in meconium aspiration syndrome found no difference in mortality or in other outcomes [134]. A subgroup analysis demonstrated a significant reduction of the need for ECMO in babies treated with surfactant (RR0.64, 95\% CI 0.46-0.91; NNT 6). Given these unsatisfactory results, bronchoalveolar lavage with diluted surfactant has been studied and seems promising [135]. Very recently, an international multicentre study randomised 66 neonates with meconium aspiration syndrome to receive either bronchoalveolar lavage with diluted surfactant in two large aliquots of $15 \mathrm{~mL} \cdot \mathrm{kg}^{-1}$ or standard care. Lavage led to a significant reduction $(-21 \%)$ in mortality or need for ECMO (OR $0.24,95 \%$ CI $0.06-0.97$ ) and to a more rapid decrease in mean airway pressure, with no substantial adverse effects [136].
Since surfactant inactivation has been reported in pneumonia or sepsis with respiratory failure, replacement therapy has been tried: improvement in gas exchange and reduction in the need for ECMO has been demonstrated, although only in small populations [131].

Similar data in the literature suggest the use of surfactant for pulmonary haemorrhage, but only a few retrospective and observational reports have documented a beneficial effect and its magnitude is unclear [131]. Surfactant replacement therapy is practically useless in congenital diaphragmatic hernia [137]

Experience with surfactant beyond the neonatal age is more limited. In 2007, six trials has been published and their metaanalysis showed reduced mortality (RR 0.7, 95\% CI 0.4-0.97; $\mathrm{p}=0.04)$, increased ventilator-free days (+2.5 days, $95 \%$ CI $0.3-4.6$; $\mathrm{p}=0.02)$ and reduced duration of ventilation (-2.3 days, 95\% CI 0.1-4.4; p=0.04) [138]. Nevertheless, populations enrolled in these trials were not homogeneous; moreover, surfactant dosing and administration varied considerably [138]. In particular, three trials enrolled babies with RSVrelated respiratory failure and, in this subgroup, a recent Cochrane meta-analysis found a reduced ICU length of stay and confirmed the decrease in ventilator days [139]. Nevertheless, no recommendations are provided, as questions are still open about surfactant preparation, appropriate dose and administration interval, and the ventilator strategy to choice. Moreover, since surfactant replacement therapy is not efficacious in adults with ARDS, it remains to be clarified whether an age cut-off can predict the outcome. ARDS pathophysiology is not homogeneous [83] and more basic research must be conducted to identify babies who can possibly benefit from surfactant therapy.

Bronchoalveolar lavage with diluted surfactant has been attempted in children with severe aspiration syndrome and respiratory failure: oxygenation improvement and reduced duration of ventilation were observed [140] but this is a preliminary study needing further investigation.

\section{MISCELLANEOUS \\ Heliox}

Many anecdotical reports describe the use of a mixture of helium and oxygen during obstructive respiratory diseases of various origin [141]. Heliox is most effective during conditions involving density-dependent increases in airway resistance, especially when used early. Any therapeutic effect of heliox on gas exchange and work of breathing should be evident soon after the treatment commences [141].

In a recent crossover trial, enrolling only 13 ventilated infants with RSV bronchiolitis, heliox reduced respiratory system resistance without an effect on gas exchange [142]. Heliox has also regained interest in the literature because of its possible use during noninvasive ventilation. A short-term crossover study in infants with RSV bronchiolitis treated with CPAP demonstrated a better $\mathrm{CO}_{2}$ clearance and clinical improvement using heliox instead of air/oxygen [143]. A recent review of treatment options for bronchiolitis highlights that heliox failed to improve major clinical outcomes [144].

A recent systematic review of heliox during severe croup gave no improvements in major outcomes [145]. This was mainly 


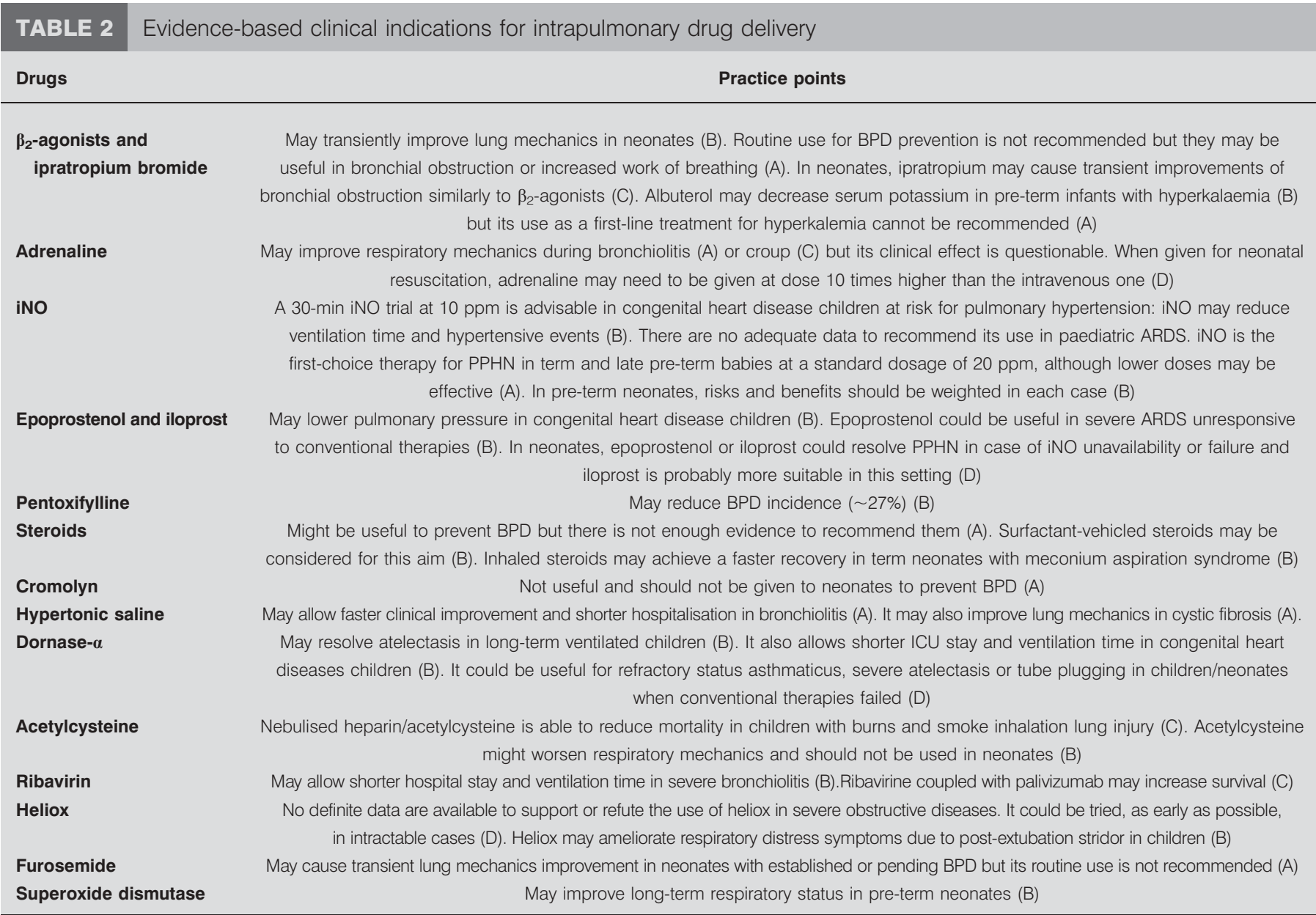

Letters in parentheses represent levels of evidence and grades of recommendations modified from the Scottish Intercollegiate Guidelines Network (SIGN) guidelines [163] as follows. A: at least one high-quality meta-analysis of randomised controlled trials (RCT) or a sufficiently powered high-quality RCT. B: other meta-analysis of RCTs or a high quality systematic review of case-control studies or a low grade RCT, but with high probability that the relationship is causal. C: a well conducted case-control or cohort study with a low risk of confounding bias. D: evidence from case series, case reports or expert opinion. iNO: inhaled nitric oxide; BPD: bronchopulmonary dysplasia; ARDS: acute respiratory distress syndrome; PPHN: persistent pulmonary hypertension of the neonate; ICU: intensive cure unit.

due to the paucity of data (only two trials) and to the significant heterogeneity in the trial methodologies. An expanded review of 50 studies other than randomised trialsregarding the use of heliox for croup in the emergency department concludes that there is no evidence to support this intervention [146].

Nonetheless, because of its physical properties (viscosity lower than air) heliox may overcome high airway resistances, improving $\mathrm{CO}_{2}$ clearance and enhance drug delivery by nebulisation [147, 148]. A recent Cochrane meta-analysis of 10 trials in children with severe asthma found heliox useless in nonintubated patients, but showed some benefits in the more critically ill patients [149].

Heliox has also been anedoctically successful in treating some children and neonates with acquired or congenital upper airway obstruction [150-152]. An early trial on children with post-extubation stridor compared heliox against the usual gas mixture and found heliox to cause a $38 \%$ reduction in respiratory distress score [153].
Heliox may improve iNO delivery in interstitial emphysema [154] and improve respiratory mechanics in ventilator dependent neonates at high risk for BPD [155]. In this population, MigLiori et al. [155] found that the use of heliox improved $\mathrm{CO}_{2}$ elimination, increased minute ventilation and reduced patient work of breathing in ventilated infants with BPD.

\section{Furosemide}

Nebulised furosemide has been used for its theoretical bronchodilator and anti-inflammatory effects, which are mainly due to the inhibition of the $\mathrm{Na}^{+} / \mathrm{K}^{+}$-ATPase across airway cell membranes [79]. However, a clinical trial of inhaled furosemide in pre-term infants with established or evolving BPD yielded inconclusive findings [156, 157]. Furosemide improves compliance and tidal volume transiently, $\leqslant 6 \mathrm{~h}$ from administration [79]. It is also free from any adverse effects on electrolyte and fluid balance compared to the intravenous route [158]. Nonetheless, these studies enrolled small populations, did not address any major outcomes, have not been replicated more recently and effective drug delivery to the 
alveoli has never been studied [79]. Therefore, a recent Cochrane meta-analysis, pooling data from all studies, does not recommend the routine furosemide nebulisation in preterm infants [159].

\section{Superoxide dismutase}

Copper-zinc superoxide dismutase (CuZnSOD) is a natural potent antioxidant enzyme. It has been administered to preterm neonates in two trials, but a meta-analysis failed to demonstrate improvements in terms of BPD reduction or other major outcomes [160]. However, treated infants had lower incidence of wheezing, asthma and other respiratory problems after hospital discharge [160]. These findings have been confirmed by a subsequent trial in which 302 pre-term infants were randomised to receive recombinant human (r-hu-) CuZnSOD every $48 \mathrm{~h}$ until their weaning from mechanical ventilation. The treatment reduced respiratory problems and hospitalisations at $1 \mathrm{yr}$ of age [161].

\section{CONCLUSIONS}

Direct lung administration allows immediate drug availability and this is potentially helpful in many critical situations in paediatric and neonatal ICUs. Nevertheless, pharmacokinetic data and controlled studies are lacking and the experience is often anecdotal. Some other issues also demand further attention. For instance, devices used for aerosolised delivery have not been subjected to the same rigorous regulation of medications. Moreover, both delivery devices and ventilators continue to evolve towards an increasingly complex technology and, finally, factors influencing drug delivery during noninvasive ventilation are not fully understood [162] This makes it even more difficult to provide definite recommendations for all circumstances. The evidence for or against each drug is summarised in table 2 with practical advice for readers [163].

\section{STATEMENT OF INTEREST}

None declared.

\section{REFERENCES}

1 Biron A. Indications of aerosol therapy in pediatrics. Prog Med (Paris) 1951; 79: 603-607.

2 Darlow BA, Mogridge N, Horwood LJ, et al. Admission of all gestations to a regional neonatal unit versus controls: neonatal morbidity. J Paediatr Child Health 2009; 45: 181-186.

3 Chavasse RJPG, Seddon P, Bara A, et al. Short acting $\beta_{2}$-agonists for recurrent wheeze in children under two years of age. Cochrane Database Syst Rev 2002; 3: CD002873.

4 Denis D, Fayon MJ, Berger P, et al. Prolonged moderate hyperoxia induces hyperresponsiveness and airway inflammation in newborn rats. Pediatr Res 2001; 50: 515-519.

5 Carroll CL, Stoltz P, Schramm CM, et al. $\beta_{2}$-adrenergic receptor polymorphisms affect response to treatment in children with severe asthma exacerbations. Chest 2009; 135: 1186-1192.

6 Gadomski AM, Bhasale AL. Bronchodilators for bronchiolitis. Cochrane Database Syst Rev 2006; 3: CD001266.

7 Gomez-Del Rio M, Gerhardt T, Hehre D, et al. Effect of a $\beta$ agonist nebulization on lung function in neonates with increased pulmonary resistance. Pediatr Pulmonol 1986; 2: 287-291.

8 Pantalitschka T, Poets CF. Inhaled drugs for the prevention and treatment of bronchopulmonary dysplasia. Pediatr Pulmonol 2006; 41: 703-708.
$9 \mathrm{Ng}$ GY, da Silva O, Ohlsson A. Bronchodilators for the prevention and treatment of chronic lung disease in preterm infants. Cochrane Database Syst Rev 2001; 3: CD003214.

10 Ballard J, Lugo RA, Salyer JW. A survey of albuterol administration practices in intubated patients in the neonatal intensive care unit. Respir Care 2002; 47: 31-38.

11 Panitch HB, Keklikian EN, Motley RA, et al. Effect of altering smooth muscle tone on maximal expiratory flows in patients with tracheomalacia. Pediatr Pulmonol 1990; 9: 170-176.

12 O'Hare FM, Molloy EJ. What is the best treatment for hyperkalaemia in a preterm infant? Arch Dis Child 2008; 93 174-176.

13 Singh BS, Sadiq HF, Noguchi A, et al. Efficacy of albuterol inhalation in treatment of hyperkalaemia in premature neonates. J Pediatr 2002; 141: 16-20.

14 Vemgal $\mathrm{P}$, Ohlsson A. Interventions for non-oliguric hyperkalaemia in preterm neonates. Cochrane Database Syst Rev 2007; 24: CD005257.

15 Osmond MH, Klassen TP. Efficacy of ipratropium bromide in acute childhood asthma: a meta-analysis. Acad Emerg Med 1995 2: 651-656.

16 Lord J, Ducharme FM, Stamp RJ, et al. Cost effectiveness analysis of inhaled anticholinergics for acute childhood and adolescent asthma. BMJ 1999; 319: 1470-1471.

17 Goggin N, Macarthur C, Parkin PC. Randomized trial of the addition of ipratropium bromide to albuterol and corticosteroid therapy in children hospitalized because of an acute asthma exacerbation. Arch Pediatr Adolesc Med 2001; 155: 1329-1334.

18 Everard M, Bara A, Kurian M, et al. Anticholinergic drugs for wheeze in children under the age of two years. Cochrane Database Syst Rev 2005; 3: CD001279.

19 Browne GJ, Trieu L, Van Asperen P. Randomized, double-blind, placebo-controlled trial of intravenous salbutamol and nebulized ipratropium bromide in early management of severe acute asthma in children presenting to an emergency department. Crit Care Med 2002; 30: 448-453.

20 Lee H, Arnon S, Silverman M. Bronchodilator aerosol administered by metered dose inhaler and spacer in subacute neonatal respiratory distress syndrome. Arch Dis Child Fetal Neonatal Ed 1994; 70: F218-F222.

21 Fayon M, Tayara N, Germain C, et al. Efficacy and tolerance of high-dose inhaled ipratropium bromide vs. terbutaline in intubated premature human neonates. Neonatology 2007; 91: 167-173.

22 Hartling L, Wiebe N, Russel K, et al. A meta-analysis of randomized controlled trials evaluating the efficacy of epinephrine for the treatment of acute viral bronchiolitis. Arch Pediatr Adolesc Med 2003; 157: 957-964.

23 Wainwright C, Altamirano L, Cheney M, et al. A multicenter, randomized, double-blind, controlled trial of nebulized epinephrine in infants with acute bronchiolitis. N Engl J Med 2003 349: 27-35.

24 Plint AC, Johnson DW, Patel $\mathrm{H}$, et al. Epinephrine and dexamethasone in children with bronchiolitis. N Engl J Med 2009; 360: 2079-2089.

25 Langley JM, Smith MB, LeBlanc JC, et al. Racemic epinephrine compared to salbutamol in hospitalized young children with bronchiolitis; a randomized controlled clinical trial (ISRCTN46561076). BMC Pediatrics 2005; 5: 7

26 Mull CC, Scarfone RJ, Ferri LR, et al. A randomized trial of nebulized epinephrine versus albuterol in the emergency departement treatment of bronchiolitis. Arch Pediatr Adolesc Med 2004; 158: 113-118.

27 Walsh P, Caldwell J, McQuillan KK, et al. Comparison of nebulized epinephrine to albuterol in bronchiolitis. Acad Emerg Med 2008; 15: 305-313. 
28 Barr FE, Patel NR, Newth CJ. The pharmacologic mechanism by which inhaled epinephrine reduces airway obstruction in respiratory syncytial virus-associated bronchiolitis. I Pediatr 2000; 136: 699-700.

29 Wohl ME, Chernick V. State of the art: bronchiolitis. Am Rev Respir Dis 1978; 118: 759-781.

30 Levin DL, Garg A, Hall LJ, et al. A prospective randomized controlled blinded study of three bronchodilators in infants with respiratory syncytial virus bronchiolitis on mechanical ventilation. Pediatr Crit Care Med 2008; 9: 598-604.

31 Argent AC, Hatherill M, Newth CJ, et al. The effect of epinephrine by nebulisation on measures of airway obstruction in patients with acute severe croup. Intensive Care Med 2008; 34: 138-147.

32 Kao B, Stewart de Ramirez SA, Belfort MB, et al. Inhaled epinephrine for the treatment of transient tachypnea of the newborn. J Perinatol 2008; 28: 205-210.

33 Courtney SE, Wachtl JP, Hopson JF, et al. Effect of racemic epinephrine on ventilatory function in the neonate postextubation. Pediatr Res 1987; 21: 381-385.

34 Davies MW, Davis PG. Nebulized racemic epinephrine for extubation of newborn infants. Cochrane Database Syst Rev 2002; 1: CD000506.

35 Kanesh Gonduri K. New approaches for persistent pulmonary hypertension of newborn. Clin Perinatol 2004; 31: 591-611.

36 Finer NN, Barrington KJ. Nitric oxide for respiratory failure in infants born at or near term. Cochrane Database Syst Rev 2006; 4: CD000399.

37 American Academy of Pediatrics Committee on Fetus and Newborn. Use of inhaled nitric oxide. Pediatrics 2000; 106: 344-345.

38 Kinsella JP, Truog WE, Walsh WF, et al. Randomized, multicenter trial of inhaled nitric oxide and high-frequency oscillatory ventilation in severe, persistent pulmonary hypertension of the newborn. J Pediatr 1997; 131: 55-62.

39 Kinsella JP, Dunbar Ivy D, Abman SH. Pulmonary vasodilator therapy in congenital diaphragmatic hernia: acute, late, and chronic pulmonary hypertension. Semin Perinatol 2005; 29: 123-128.

40 Greenough A, Ketriwal B. Pulmonary hypertension in the newborn. Pediatr Resp Rev 2005; 6: 111-116.

41 Cannon BC, Feltes TF, Fraley JK, et al. Nitric oxide in the evaluation of congenital heart disease with pulmonary hypertension: factors related to nitric oxide response. Pediatr Cardiol 2005; 26: 565-569.

42 González A, Fabres J, D’Apremont I, et al. Randomized controlled trial of early compared with delayed use of inhaled nitric oxide in newborns with a moderate respiratory failure and pulmonary hypertension. J Perinatol 2010; 30: 420-424.

43 Konduri Ganesh G, Solimano A, Sokol GM, et al. A randomized trial of early versus standard inhaled nitric oxide therapy in term and near-term newborn infants with hypoxic respiratory failure. Pediatrics 2004; 113: 559-564.

44 Demirakca S, Dotsch J, Knothe C, et al. Inhaled nitric oxide in neonatal and pediatric acute respiratory distress syndrome: dose response, prolonged inhalation and weaning. Crit Care Med 1996; 24: 1913-1919.

45 Macrae DJ, Field D, Mercier JC, et al. Inhaled nitric oxide therapy in neonates and children: reaching a European consensus. Intensive Care Med 2004; 30: 372-380.

46 Barrington KJ, Finer NN. Inhaled nitric oxide for preterm infants: a systematic review. Pediatrics 2007; 120: 1088-1099.

47 Mercier JC, Hummler H, Durrmeyer X, et al. The effects of inhaled nitric oxide on the development of bronchopulmonary dysplasia in preterm infants: the EUNO clinical trial. Arch Dis Child 2008; 93: Suppl. 2, espr22.
48 Watson RS, Clermont G, Kinsella JP, et al. Clinical and economics effect of iNO in premature newborns with respiratory failure at 1 year. Pediatrics 2009; 124: 1333-1343.

49 Dellinger RP, Zimmerman JL, Taylor RW, et al. Effects of inhaled nitric oxide in patients with acute respiratory distress syndrome: results of a randomized phase II trial. Crit Care Med 1998; 26: 15-23.

50 Miller OI, Tang SF, Keech A, et al. Inhaled nitric oxide and prevention of pulmonary hypertension after congenital heart surgery: a randomised double blind study. Lancet 2000; 356: 1464-1469.

51 Patel NR, Hammer J, Nichani S, et al. Effect of inhaled nitric oxide on respiratory mechanics in ventilated infants with RSV bronchiolitis. Intensive Care Med 1999; 25: 81-87.

52 Howard LS, Morrell NW. New therapeutic agents for pulmonary vascular diseases. Pediatr Respir Rev 2005; 6: 285-291.

53 Schermuly RT, Inholte C, Ardeschir Ghofrani H, et al. Lung vasodilatory response to inhaled iloprost in experimental pulmonary hypertension: amplification by different type phosphodiesterase inhibitors. Respir Res 2005; 6: 76.

54 Soditt V, Aring C, Groneck P. Improvement of oxygenation induced by aerosolized prostacyclin in a preterm infant with persistent pulmonary hypertension of the newborn. Intensive Care Med 1997; 23: 1275-1278.

55 De Jaegere AP, van den Anker JN. Endotracheal instillation of prostacyclin in preterm infants with persistent pulmonary hypertension. Eur Respir J 1998; 12: 932-934.

56 Kelly LK, Porta NF, Goodman DM, et al. Inhaled prostacyclin for term infants with persistent pulmonary hypertension refractory to inhaled nitric oxide. J Pediatr 2002; 141: 830-832.

57 De Luca D, Zecca E, Piastra M, et al. Iloprost as "rescue" therapy for pulmonary hypertension of the neonate. Paediatr Anaesth 2007; 17: 394-395.

58 Sood BG, Delaney-Black V, Aranda JV, et al. Aerosolized PGE 1 : a selective pulmonary vasodilator in neonatal hypoxemic respiratory failure: results of a phase I/II open label clinical trial. Pediatr Res 2004; 56: 579-585.

59 Lowson SM. Inhaled alternatives to nitric oxide. Crit Care Med 2005; 33: Suppl. 3, S188-S195.

60 Eifinger F, Sreeram N, Mehler K, et al. Aerosolized iloprost in the treatment of pulmonary hypertension in extremely preterm infants: a pilot study. Klin Padiatr 2008; 220: 66-69.

61 Rimensberger PC, Spahr-Schopfer I, Berner M, et al. Inhaled nitric oxide versus aerosolized iloprost in secondary pulmonary hypertension in children with congenital heart disease Vasodilator capacity and cellular mechanisms. Circulation 2001 103: 544-548.

62 Rashid A, Ivy D. Severe paediatric pulmonary hypertension: new management strategies. Arch Dis Child 2005; 90: 92-98.

63 Dahlem P, van Aalderen VM, de Neef M, et al. Randomised controlled trial of aerosolized prostacycline therapy in children with acute lung injury. Crit Care Med 2004; 32: 1055-1060.

64 Moya MP, Gow AJ, Califf RM, et al. Inhaled ethyl nitrite gas for persistent pulmonary hypertension of the newborn. Lancet 2002; 360: 141-143.

65 Gaston B, Reilly J, Drazen JM, et al. Endogenous nitrogen oxides and bronchodilator S-nitrosothiols in human airways. Proc Natl Acad Sci USA 1993; 90: 10957-10961.

66 Lauterbach R, Szymura-Oleksiak J. Nebulized pentoxiphylline in successful treatment of five premature neonates with bronchopulmonary dysplasia. Eur J Pediatr 1999; 158: 607-610.

67 Lauterbach R, Pawlik D, Kowalczyk D, et al. Effect of the immunomodulating agent, pentoxifylline, in the treatment of sepsis in prematurely delivered infants: a placebo-controlled, double-blind trial. Crit Care Med 1999; 27: 807-814.

68 ter Horst SAJ, Wagenaar GTM, de Boer E, et al. Pentoxifylline reduces fibrin deposition and prolongs survival in neonatal hyperoxic lung injury. J Appl Physiol 2004; 97: 2014-2019. 
69 Lauterbach R, Szymura-Oleksiak J, Pawlik D, et al. Nebulized pentoxifylline for prevention of bronchopulmonary dysplasia in very low birth weight infants: a pilot clinical study. J Matern Fetal Neonatal Med 2006; 19: 433-438.

70 Haque K, Mohan P. Pentoxifylline for neonatal sepsis. Cochrane Database Syst Rev 2003; 4: CD004205.

71 Patole S. Prevention and treatment of necrotising enterocolitis in preterm neonates. Early Hum Dev 2007; 83: 635-642.

72 Shah V, Ohlsson A, Halliday HL, et al. Early administration of inhaled corticosteroids for preventing chronic lung disease in ventilated very low birth weight preterm neonates. Cochrane Database Syst Rev 2007; 4: CD001969.

73 Shah SS, Ohlsson A, Halliday H, et al. Inhaled versus systemic corticosteroids for the treatment of chronic lung disease in ventilated very low birth weight preterm infants. Cochrane Database Syst Rev 2007; 6: CD002057.

74 Bassler D, Halliday HL, Plavka R, et al. The Neonatal European Study of Inhaled Steroids (NEUROSIS): an EU-funded international randomised controlled trial in preterm infants. Neonatology 2009; 97: 52-55.

75 Yeh TF, Lin HC, Chang C, et al. Early intratracheal instillation of budesonide using surfactant as vehicle to prevent chronic lung disease in preterm infants: a pilot study. Pediatrics 2008; 121 : e1310-1318.

76 Tripathi S, Saili A, Dutta R. Inflammatory markers in meconium induced lung injury in neonates and effect of steroids on their levels: a randomized controlled trial. Indian J Med Microbiol 2007, 25: 103-107.

77 Tripathi S, Saili A. The effect of steroids on the clinical course and outcome of neonates with meconium aspiration syndrome. J Trop Pediatr 2007; 53: 8-12.

78 Basu S, Kumar A, BhatiaBD, et al. Role of steroids on the clinical course and outcome of meconium aspiration syndrome-a randomized controlled trial. J Trop Pediatr 2007; 53: 331-337.

79 Fok TF. Adjunctive pharmacotherapy in neonates with respiratory failure. Semin Fetal Neonat Med 2009; 14: 49-55.

80 Viscardi RM, Hasday JD, Gumpper KF, et al. Cromolyn sodium prophylaxis inhibits pulmonary proinflammatory cytokines in infants at high risk for bronchopulmonary dysplasia. Am J Respir Crit Care Med 1997; 156: 1523-1529.

81 Watterberg KL, Murphy S. Failure of cromolyn sodium to reduce the incidence of bronchopulmonary dysplasia: a pilot study. The Neonatal Cromolyn Study Group. Pediatrics 1993; 91: 803-806.

$82 \mathrm{Ng}$ GY, Ohlsson A. Cromolyn sodium for the prevention of chronic lung disease in preterm infants. Cochrane Database Syst Rev 2001; 2: CD003059.

83 De Luca D, Minucci A, Cogo P, et al. Secretory phospholipase A2 pathway during pediatric ARDS: a preliminary study. Pediatr Crit Care Med 2010; [Epub ahead of print DOI: 10.1097/ pcc.0b013e3181dbe95e].

84 Ramsay PL, DeMayo FJ, Hegemier SE, et al. Clara Cell secretory protein oxidation and expression in premature infants who develop bronchopulmonary dysplasia. Am J Respir Crit Care Med 2001; 164: 155-161.

85 Johansson S, Kristjánsson S, Bjarnarson SP, et al. Clara cell protein 16 (CC16) serum levels in infants during respiratory syncytial virus infection. Acta Paediatr 2009; 98: 579-581.

86 Sengler C, Heinzmann A, Jerkic SP, et al. Clara cell protein 16 (CC16) gene polymorphism influences the degree of airway responsiveness in asthmatic children. J Allergy Clin Immunol 2003; 111: 515-519.

87 Jorens PG, Sibille Y, Goulding NJ, et al. Potential role of Clara cell protein, an endogenous phospholipase A2 inhibitor, in acute lung injury. Eur Respir J 1995; 8: 1647-1653.

88 Levine CR, Gewolb IH, Allen K, et al. The safety, pharmacokinetics, and anti-inflammatory effects of intratracheal recombinant human Clara cell protein in premature infants with respiratory distress syndrome. Pediatr Res 2005; 58: 15-21.

89 American Heart Association, American Academy of Pediatrics. 2005 American Heart Association (AHA) Guidelines for Cardiopulmonary Resuscitation (CPR) and Emergency Cardiovascular Care (ECC) of pediatric and neonatal patients: Pediatric Advanced Life Support. Pediatrics 2006; 117: e1005-e1028.

90 The International Liaison Committee on Resuscitation. The International Liaison Committee on Resuscitation (ILCOR) Consensus on science with treatment recommendations for pediatric and neonatal patients: neonatal resuscitation. Pediatrics 2006; 117: e978-e988.

91 Choong K, Bohn D, Fraser DD, et al. Vasopressin in pediatric vasodilatory shock. A multicenter randomized controlled trial. Am J Resp Crit Care Med 2009; 180: 632-639.

92 Kleinman ME, Oh W, Stonestreet BS. Comparison of intravenous and endotracheal epinephrine during cardiopulmonary resuscitation in newborn piglets. Crit Care Med 1999; 27: 2748-2754.

93 Mandelberg A, Tal G, Witzling M, et al. Nebulized hypertonic saline solution treatment in hospitalized infants with viral bronchiolitis. Chest 2003; 123: 481-487.

94 Zhang L, Mendoza-Sassi RA, Wainwright C, et al. Nebulized hypertonic saline solution for acute bronchiolitis in infants. Cochrane Database Syst Rev 2008; 4: CD006458.

95 Wark P, McDonald VM. Nebulised hypertonic saline for cystic fibrosis. Cochrane Database Syst Rev 2009; 2: CD001506.

96 Riethmueller J, Borth-Bruhns T, Kumpf M, et al. Recombinant human deoxyribonuclease shortens ventilation time in young, mechanically ventilated children. Pediatr Pulmonol 2006; 41: 61-66.

97 Riethmueller J, Kumpf M, Borth-Bruhns T, et al. Clinical and in vitro effect of dornase alfa in mechanically ventilated pediatric non-cystic fibrosis patients with atelectases. Cell Physiol Biochem 2009; 23: 205-210.

98 Prodhan P, GreenbergB, Bhutta AT, et al. Recombinant human deoxyribonuclease improves atelectasis in mechanically ventilated children with cardiac disease. Congenit Heart Dis 2009; 4: 166-173.

99 Patel A, Harrison E, Durward A, et al. Intratracheal human deoxyribonuclease in acute life-threatening asthma refractory to conventional treatment. Br J Anaesth 2000; 84: 505-507.

100 Puterman AS, Weinberg EG. rhDNase in acute asthma. Paediatr Pulmonol 1997; 23: 316-331.

101 Greally P. Human recombinant DNase for mucous plugging in status asthmaticus. Lancet 1995; 346: 1423-1424.

102 Durward A, Forte V, Shemie S. Resolution of mucous plugging and atelectasis after intratracheal rhDNase therapy in a mechanically ventilated child with refractory status asthmaticus. Crit Care Med 2000; 27: 560-562.

103 El Hassan NO, Chess PR, Huysman MWA, et al. Rescue use of DNase in critical lung atelectasis and mucus retention in premature neonates. Pediatrics 2001;108; 468-470.

104 Erdeve O, Uras N, Atasay B, et al. Efficacy and safety of nebulized recombinant human DNAase as rescue treatment for persistent atelectasis in newborns: case-series. Croat Med J 2007; 48: 234-129.

105 Desai MH, Mlcak R, Richardson J, et al. Reduction in mortality in pediatric patients with inhalation injury with aerosolized heparin/N-acetylcystine [correction of acetylcystine] therapy. J Burn Care Rehabil 1998; 19: 210-212.

106 Bibi H, Seifert B, Oullette M, et al. Intratracheal N-acetylcysteine use in infants with chronic lung disease. Acta Paediatr 1992; 81: 335-339.

107 Purcell K, Fergie J. Driscoll Children's Hospital respiratory syncytial virus database: risk factors, treatment and hospital course in 3308 infants and young children, 1991 to 2002. Pediatr Infect Dis J 2004; 23: 418-423. 
108 Davison C, Ventre KM, Luchetti M, et al. Efficacy of interventions for bronchiolitis in critically ill infants: a systematic review and meta-analysis. Pediatr Crit Care Med 2004; 5: 482-489.

109 Ventre K, Randolph AG. Ribavirin for respiratory syncytial virus infection of the lower respiratory tract in infants and young children. Cochrane Database Syst Rev 2007; 1: CD000181.

110 Chávez-Bueno S, Mejías A, Merryman RA, et al. Intravenous palivizumab and ribavirin combination for respiratory syncytial virus disease in high-risk pediatric patients. Pediatr Infect Dis J 2007; 26: 1089-1093.

111 Hiddens T. Inhaled antibiotics. Pediatr Pulmonoldel, 2004: Suppl. 26, 92-94.

112 Michalopoulos A, Papadakis E. Inhaled anti-infective agents: emphasis on colistin. Infection 2010; 38: 81-88.

113 Chuchalin A, Eszter C, Gyurkovics K, et al. A formulation of aerosolized tobramycin (Bramitob) in the treatment of patients with cystic fibrosis and Pseudomonas aeruginosa infection. Pediatr Drugs 2007; 9: Suppl. 1, 21-31.

114 Ratjen F, Munck A, Kho P, et al. Treatment of early Pseudomonas aeruginosa infection in patients with cystic fibrosis: the ELITE trial. Thorax 2010; 65: 286-291.

115 O'Sullivan BP, Yasothan U, Kirkpatrick P. Inhaled aztreonam. Nat Rev Drug Discov 2010; 9: 357-358.

116 Elborn JS, Henig NR. Optimal airway antimicrobial therapy for cystic fibrosis: the role of inhaled aztreonam lysine. Expert Opin Pharmacother 2010; 11: 1373-1385.

117 Gibson RL, Emerson J, Mayer-Hamblett N, et al. Duration of treatment effect after tobramycin solution for inhalation in young children with cystic fibrosis. Pediatr Pulmonol 2007; 42: 610-623.

118 Noah TL, Ivins SS, Abode KA, et al. Inhaled versus systemic antibiotics and airway inflammation in children with cystic fibrosis and Pseudomonas. Pediatr Pulmonol 2010; 45: 281-290.

119 Yang Y, Tsifansky MD, Wu CJ, et al. Inhalable antibiotic delivery using a dry powder co-delivering recombinant deoxyribonuclease and ciprofloxacin for treatment of cystic fibrosis. Pharm Res 2010; 27: 151-160.

120 Doring G, Hoiby N. Early intervention and prevention of lung disease in cystic fibrosis: a European consensus. J Cystic Fibrosis 2004; 3: 67-91.

121 Wood DM, Smyth AR. Antibiotic strategies for eradicating Pseudomonas aeruginosa in people with cystic fibrosis. Cochrane Database Syst Rev 2006; 1: CD004197.

122 Muttil P, Wang C, Hickey AJ. Inhaled drug delivery for tuberculosis therapy. Pharm Res 2009; 26: 2401-2416.

123 Falagas ME, Siempos II, Bliziotis IA, et al. Administration of antibiotics via the respiratory tract for the prevention of ICUacquired pneumonia: a meta-analysis of comparative trials. Crit Care 2006; 10: R123.

124 Robinson BRH, Athota KP, Branson RD. Inhalational therapies for the ICU. Curr Opin Crit Care 2009; 15: 1-9.

125 Palmer LB. Aerosolized antibiotics in critically ill ventilated patients. Curr Opin Crit Care 2009; 15: 413-418.

126 Kuiper L, Ruijgrok EJ. Review on the clinical use of inhaled amphotericin B. J Aerosol Med Pulm Drug Del 2009; 22: 213-227.

127 Sanmartín E, Morales P, Monte E, et al. A comparision of several formats of amphotericin $\mathrm{B}$ as an inhaled antifungal prophylaxis. Transplant Proc 2009; 41: 2225-2226.

128 Morales P, Galán G, Sanmartín E, et al. Intrabronchial instillation of amphotericin B lipid complex: a case report. Transplant Proc 2009; 41: 2223-2224.

129 Eiland LS, Eiland EH. Zanamivir for the prevention of influenza in adults and children age 5 years and older. Therap Clin Risk Manag 2007; 3: 461-465.

130 Imuta F, Toyoda M, Toyoda T. New application method of zanamivir with a straw. Pediatr Int 2003; 45: 366-367.
131 Engle WA, the Committee on Fetus and Newborn. Surfactantreplacement therapy for respiratory distress in the preterm and term neonate. Pediatrics 2008;121;419-432.

132 Sweet D, Bevilacqua G, Carnielli VP, et al. European consensus guidelines on the management of neonatal respiratory distress sindrome. J Perinat Med 2007; 35: 175-186.

133 Soll R, Özek E. Multiple versus single doses of exogenous surfactant for the prevention or treatment of neonatal respiratory distress syndrome. Cochrane Database Syst Rev 2006; 1: CD001694.

134 El Shahed AI, Dargaville PA, Ohlsson A, et al. Surfactant for meconium aspiration syndrome in full term/near term infants. Cochrane Database Syst Rev 2007; 3: CD002054.

135 Dargaville PA, Mills JF, Copnell B, et al. Therapeutic lung lavage in meconium aspiration syndrome: a preliminary report J Paediatr Child Health 2007; 43: 539-545.

136 Dargaville PA, Copnell B, Mills JF, et al. Randomized controlled trial of lung lavage with dilute surfactant for meconium aspiration syndrome. J Pediatr 2010; [Epub ahead of print DOI: 10.1016/j.jpeds.2010.08.044].

137 Cogo PE, Zimmermann LJ, Rosso F, et al. Surfactant synthesis and kinetics in infants with congenital diaphragmatic hernia. Am J Respir Crit Care Med 2002; 166: 154-158.

138 Duffett $\mathrm{M}$, Choong $\mathrm{K}, \mathrm{Ng} \mathrm{V}$, et al. Surfactant therapy for acute respiratory failure in children: a systematic review and metaanalysis. Critical Care 2007; 11: R66.

139 Ventre K, Haroon M, Davison C. Surfactant therapy for bronchiolitis in critically ill infants. Cochrane Database Syst Rev 2006; 3: CD005150.

140 Marraro GA, Luchetti M, Spada C, et al. Selective medicated (normal saline and exogenous surfactant) bronchoalveolar lavage in severe aspiration syndrome in children. Pediatr Crit Care Med 2007; 8: 476-481.

141 Gupta VK, Cheifetz IM. Heliox administration in the pediatric intensive care unit: an evidence-based review. Pediatr Crit Care Med 2005; 6: 204-211.

142 Kneyber MC, van Heerde M, Twisk JW, et al. Heliox reduces respiratory system resistance in respiratory syncytial virus induced respiratory failure. Crit Care 2009; 13: R71.

143 Martinón-Torres F, Rodríguez-Núñez A, Martinón-Sánchez JM. Nasal continuous positive airway pressure with heliox versus air/oxygen in infants with acute bronchiolitis: a crossover study. Pediatrics 2008; 121: e1190-e1195.

144 Yanney M, Vyas H. The treatment of bronchiolitis. Arch Dis Child 2008; 93: 793-798.

145 Vorwerk C, Coats TJ. Use of helium-oxygen mixtures in the treatment of croup: a systematic review. Emerg Med J 2008; 25: 547-550.

146 Vorwerk C, Coats T. Best evidence topic reports: heliox in croup. Emerg Med J 2008; 25: 365-366.

147 Myers TR. Therapeutic gases for neonatal and pediatric respiratory care. Respir Care 2003; 48: 399-422.

148 Garner SS, Wiest DB, Stevens CE, et al. Effect of heliox on albuterol delivery by metered-dose inhaler in pediatric in vitro models of mechanical ventilation. Pharmacotherapy 2006; 26: 1396-1402.

149 Rodrigo G, Pollack C, Rodrigo C, et al. Heliox for nonintubated acute asthma patients. Cochrane Database Syst Rev 2006; 4: CD002884.

150 Tsai MH, Wong KS, Lien R, et al. Heliox as the rescue therapy for a neonate with congenital tracheal stenosis, pulmonary artery sling, and intracardiac anomalies. Am J Perinatol 2009; 26: 357-360.

151 Castelló Muñoz A, Carreira Sande N, Bouzón Alejandro M, et al. [Usefulness of Heliox in the management of a serious airway obstruction caused by a subglottic hemangioma.] An Pediatr (Barc) 2007; 67: 61-64. 
152 Bigham MT, Nowak JE, Wheeler DS. Therapeutic application of helium-oxygen and mechanical ventilation in a child with acute myelogenous leukemia and airway obstruction. Pediatr Emerg Care 2009; 25: 469-472.

153 Kemper KJ, Ritz RH, Benson MS, et al. Helium-oxygen mixture in the treatment of postextubation stridor in pediatric trauma patients. Crit Care Med 1991; 19: 356-359.

154 Phatak RS, Pairaudeau CF, Smith CJ, et al. Heliox with inhaled nitric oxide: a novel strategy for severe localized interstitial pulmonary emphysema in preterm neonatal ventilation. Respir Care 2008; 53: 1731-1738.

155 Migliori C, Gancia P, Garzoli E, et al. The Effects of helium/ oxygen mixture (heliox) before and after extubation in long-term mechanically ventilated very low birth weight infants. Pediatrics 2009; 123: 1524-1528.

156 Rastogi A, Luayon M, Ajayi OA, et al. Nebulized furosemide in infants with bronchopulmonary dysplasia. J Pediatr 1994; 125: 976-979.

157 Kugelman A, Durand M, Garg M. Pulmonary effect of inhaled furosemide in ventilated infants with severe bronchopulmonary dysplasia. Pediatrics 1997; 99: 71-75.
158 Prabhu VG, Keszler M, Dhanireddy R. Pulmonary function changes after nebulised and intravenous frusemide in ventilated premature infants. Arch Dis Child Fetal Neonatal Ed 1997; 77: F32-F35.

159 Brion LP, Primhak RA, Yong W. Aerosolized diuretics for preterm infants with (or developing) chronic lung disease Cochrane Database Syst Rev 2006; 3: CD001694.

160 Suresh GK, Davis JM, Soll RF. Superoxide dismutase for preventing chronic lung disease in mechanically ventilated preterm infants. Cochrane Database Syst Rev 2001; 1: CD001968.

161 Davis JM, Parad RB, Michele T, et al. Pulmonary outcome at 1 year corrected age in premature infants treated at birth with recombinant human CuZn Superoxide Dismutase. Pediatrics 2003; $111 ; 469-476$.

162 Dhand $R$. Inhalation therapy in invasive and noninvasive mechanical ventilation. Curr Opin in Crit Care 2007; 13: 27-38.

163 Scottish Intercollegiate Guidelines Network. SIGN50: a guideline developer's handbook. www.sign.ac.uk/guidelines/fulltext/ 50/ Date last accessed: February 13, 2010. Date last updated: January 2008. 